JOURNAL OF ENGLISH STUDIES, I (1999), 165-185

\title{
A COGNITIVE VIEW ON BILINGUALISM AND "BILINGUAL" TEACHING AND LEARNING
}

\author{
SUSANNE NIEMEIER \\ University of Bremen, Germany
}

\begin{abstract}
Foreign language teaching and learning may profit substantially when discussed from a cognitive point of view. The paper deals with the situation of a new direction of foreign language teaching and learning in Germany, where in the last years so-called "bilingual" approaches have been implemented. This means that subjects such as history or biology are taught in English instead of in the mother tongue, thus exposing the learners to the foreign language to a degree that can not be offered by traditional English lessons. Furthermore, in those content subjects, the foreign language is used in a much more authentic and holistic way. So far, the results have been very promising.

Combining some reflections on this new kind of teaching with insights from cognitive linguistics seems to be a way of introducing the learners not only to more exposure to the language, but also offers a way to provide the learners with insights into the way language works as well as with insights into the conceptual world behind the foreign language, and it tries to prevent the students from generating an indiscriminate mixture between their home culture and the foreign culture.
\end{abstract}

\section{INTRODUCTION}

Cognitive linguistics is no longer in its infancy but has grown up in the last years and is now mature enough to go applied. So far, these applications seem to centre mainly around language acquisition and learning issues. The state of foreign language teaching is largely lamented -at least in Germany- and new methods and strategies are badly needed. Understanding language in the way cognitive linguistics does entails 
understanding the teaching of language in a new way as well. Starting from the assumption that nothing in language is arbitrary, it might be a good idea to make learners aware of this non-arbitrariness in order to get them to understand how the foreign language works, and not just to learn rules by heart.

Cognitive linguistics may be able to cater to at least some of these needs, especially insofar as its underlying humanistic approach fits the new theories in foreign language teaching, such as awareness raising or the action-oriented approach, very well. There is an overwhelming trend towards a more holistic kind of learning and teaching, which is not supposed to centre too much around the teacher's person but to concentrate much more on the learners: what are the learners' interests, what are their needs, what are their learning strategies and how can those be enhanced - to mention only some of the current questions. Concentrating on the concept of learning strategies is especially important because this enables the learners to thoroughly acquire, structure and retain all kinds of new knowledge. In addition, psycholinguistic and neurophysiological research has been more and more able to shed new light on the processes of learning as such and of learning a (foreign) language in particular.

In Germany, one of the current trends in teaching foreign languages is what the Germans call "bilingual teaching". In a sociolinguistic context, this term is certainly a misnomer because it refers to school subjects like history, geography, social studies etc. being taught in English (and in French, in some cases). There, the language is no longer the subject matter, but serves as the medium of instruction. Hence, there is no real bilingualism involved, given the fact that the classes are mostly held in one language only, be it in German or in the foreign language. However, the term "bilingual" education is so firmly established in German teaching methodology that we will stick to it in this context as well, especially when keeping in mind that the ultimate goal of this type of language education is to make the learners bilingual beings or at least, as bilingual as possible. Arguably, this method is not new to many European countries - Germany is certainly lagging behind in this respect. However, this method is new for Germans and the first university departments have only recently started to offer training courses for learners and teacher trainees who want to teach in one of the "bilingual" schools.

These preliminary remarks may help to explain the current interest in theories of bilingualism and "bilingual" teaching and learning. Combining this aspect with some insights from cognitive linguistics and trying to take a cognitive perspective on language teaching and learning is then only taking one further step on this road. Furthermore, taking a cognitive perspective seems to be a challenging endeavour, especially insofar as the new teaching methods may from the onset profit from insights into cognitive linguistics without having to compete with more traditional methods of language teaching. 


\section{NATURAL BILINGUALISM VS. "BILINGUAL” TEACHING AND LEARNING}

Research on bilingualism has most often focussed on natural bilingualism, i.e. either on children growing up with two languages or on the linguistic behaviour of people living in a bilingual society viz. in the context of immigration. Literature abounds with examples from nations with two or more official languages such as Canada, from nations with linguistic majorities and minorities such as Spain with Spanish and Catalan speakers in Catalonia, or from research on the status of and attitudes towards dialects, e.g. German Alsatian in the East of France near Strasbourg (cf. Artigal 1991; Canadian Education Association 1992; Cole 1975; García 1991).

This special kind of "bilingualism" that will mainly be focused upon should more precisely be called "bilingual teaching and learning". Both terms are generally used and accepted for this concept throughout Germany (cf. Schmid-Schönbein \& Siegismund 1998; Mäsch 1995). However, one should not forget that this kind of "bilinguality" does not refer to the use of two languages at a time, even though its outcome may, in an ideal case, be similar to that of a child growing up in naturally bilingual surroundings, i.e. the learners should be as bilingually efficient as possible on leaving school.

As already mentioned, this kind of "bilingual" teaching, which more and more German schools adhere to, means that subjects such as history, geography, social studies and others are taught in English to German learners. English is then no longer the focus of those lessons; rather, the contents are foregrounded. Thus, the learners' fluency in the foreign language is improving along with their knowledge about English-speaking cultures because the topics discussed would generally deal with those cultures. "Bilingual" teaching aims at giving the learners a better chance to express themselves in the other language in a quasi-authentic situation ${ }^{1}$, while at the same time offering plenty of opportunities for using the foreign language. This training necessarily leads to a better command of the foreign language. As English currently seems to be the 'unofficial' language of the European Union, learners are prepared for a European job market where English as a lingua franca is a necessary precondition for any kind of professional success, or for further studies at any English-speaking university.

Still, valuable as this idea might be, it is not imitating the process of natural bilingual learning; rather, the foreign language is learnt in a very conscious way. The learners do not go through a double acquisition phase -as children with parents from two cultures do- but learn one language on top of the other as an additive kind of bilingualism ${ }^{2}$. This

1. On the concept of authenticity in the foreign language classroom see for example Lier (1996).

2. The term "additive bilingualism" was coined by Lambert (1974) and refers to the addition of the second language to the already existant one as an enrichment. It stands in contrast to the so-called "subtractive bilingualism", which highlights how acquiring a second language may result in a loss or at least a deterioration of the first one. 
means that all kinds of interferences that may take place in natural bilingual language learning should be absent here. Literature on natural bilingual language learning abounds with examples of children using the earlier acquired linguistic form (or the structurally easier one, e.g. Vihman 1985) for both their languages until they have acquired the more complex one as well, thus, they code-switch for reasons of ease of access. This would not happen in institutional "bilingual" learning because the mother tongue has already been thoroughly acquired and serves as a kind of plateau.

However, interferences and code-switches/code-mixes ${ }^{3}$ may appear under these conditions as well, only at different points. Most of these switches/mixes should be expected at the level of vocabulary items. Thus, as soon as a learner has difficulty accessing the meaning of a concept in the foreign language, s/he would use a similar concept from the mother tongue. Saunders (1982: 46) gives the example of a 2-year-old English-German bilingual talking to his English grandfather and saying "Lots of Möwen, Grandad!", referring to seagulls.

It is here, of course, where the problems begin. Starting from the assumption that translation is impossible and that concepts are deeply culture-entrenched, we should ask ourselves if these switches/mixes indicate that the learners just take the foreign labels and stick them onto concepts from their mother tongue. The aim of institutional "bilingual" teaching should be to avoid this kind of misguided labelling activity but instead to give the learners an insight into the ways the foreign culture works and to do so as holistically as possible, i.e. without referring too much to related concepts in their home culture in order not to lead the learners to mix concepts.

\subsection{Research on natural bilingualism}

Concerning natural bilingualism, researchers have been especially interested in the phenomenon of code-switching, defined by Hoffmann (1991: 110) as involving "the alternate use of two languages or linguistic varieties within the same utterance or during the same conversation", as opposed to code-mixing and borrowing ${ }^{4}$. Generally, there

3. Holmes (1992: 50) defines the difference between code-mixing and code-switching as follows: "Codemixing suggests the speaker is mixing up codes indiscriminately or perhaps because of incompetence, whereas the switches are very well-motivated in relation to the symbolic or social meanings of the two codes." A different aspect is grasped by Hoffmann (1992: 104) who claims that "Switches occurring at the lexical level within a sentence (intra-sentential switches) are referred to as 'code-mixes' (...), changes over phrases or sentences (inter-sentential), including tags and exclamations at either end of the sentence, are called 'code-switches'...'. Pütz (1994: 138) considers code-mixing to be a subcategory of code-switching, and in the present context we will adhere to this functional definition as well.

4. Borrowing is seen by Grosjean (1982) as referring to terms that have passed from one language to another and are even used by monolinguals. 
does not seem to be a clear dividing line between code-switching and borrowing, especially not when analysing the speech of bilingual children. Thus, younger bilingual children tend to just introduce nouns from the other language (as in the Möwen example quoted above), whereas older ones seem more inclined to switch over phrases and sentences, and also use mixes at the word level (McClure 1977), such as in Fantini's (1985) example: "Yo lo voy a lokar" uttered by a six-year-old Spanish-English bilingual boy and referring to the English to lock which was morphologically adapted to Spanish, or in Reyes' (1982) example of a Mexican child living in the US (no age given): " $A$ veces, we take too many things for granted".

These findings may lead to the conclusion that bilinguals need to have already attained a certain degree of linguistic proficiency before being able to switch within the same utterance. Switching within the same utterance thus seems to be a more complicated linguistic issue than merely introducing words from the other language, because it presupposes a more complex neurological activity. It is not limited to just exchanging one lexical item for another one, but the complete sentence-internal cohesion has to be maintained, on a phonological and syntactic as well as on a morphological and suprasegmental level.

For a long time researchers were convinced that bilingualism is detrimental for children's linguistic skills in general and that minority language children show an inadequate command of both the majority and the minority language (e.g. Cummins 1984; Skutnabb-Kangas 1984, who have both analysed children of immigrant workers). On the other hand, other researchers claim that even L1 skills may become enhanced by the bilingual experience (e.g. Lambert \& Tucker 1972). This second kind of research is mainly based on results of immersion programmes ${ }^{5}$ in Canada, Wales and Catalonia. What bilingualism seems to be able to do in any case is to lead to a greater awareness of linguistic operations (Vygotsky 1962). Furthermore, the more negative evaluations may probably not be connected with the bilingual experience as such, but may be attributed to the social and economic environments of the minority language speakers (Cummins 1978b).

As to the interrelatedness of first and second language, Cummins (1978a) has formulated his Developmental Interdependence Hypothesis, suggesting that the level of second language competence a child acquires depends to a certain extent on the stage of

5. In this context, "immersion programme" refers to all school education being done in the L2. This is what is usually happening to children from the minority language group, often (as in Canada) on a voluntary basis. Baker points out that we have to differentiate between early immersion, middle immersion and late immersion, according to the age of onset of immersion education, and also between total immersion and partial immersion, according to the amount of time devoted to immersion per school day. The most popular Canadian programme is Early Total Immersion (Baker 1993: 158). 
development that has been reached in the first language. This means that the second language does not start from a tabula rasa kind of situation but is built upon already existing linguistic knowledge and skills. Furthermore, it is not just purely "linguistic" knowledge that is relevant in this respect, but all the categories that have already been formed in the children's minds while acquiring the first language. At this point, they have already developed cognitive insights, so that "meaning" is not only related to linguistic knowledge but also to extralinguistic concepts and categories of concepts. Cummins further assumes that the ability to handle tasks that are cognitively more demanding, such as understanding decontextualised language, can be successfully transferred from L1 to L2, thus the strategies of language use and language construction are activated for both languages. This, however, would advocate a later onset of the second language because those skills and strategies in the first language need some time to develop.

Connecting these insights to the current situation in Germany, where learners habitually begin to learn their second language at the age of 10 at school as a foreign language, means that we have to move away from the idea of conducting the whole of English teaching in English, banning the German language. The German language is already there, we as English teachers do not start from point zero, but should incorporate those language construction strategies and skills that the learners already possess for their mother tongue into the English lessons and try to implement those general skills. This would mean, however, that we would indeed have to teach "bilingually" in the basic sense of the word. This is certainly also true for the "bilingual" teaching and learning models which will be described below.

When children in Germany start to learn their first foreign language, most conceptual categories have already been formed in their L1. But-and this is what is most important in the current context- L1 and L2 represent two (slightly or strongly) divergent categorisation systems. In a nutshell, raising the learner's awareness concerning the divergence between those systems and at the same time keeping each of them intact is what foreign language learning and teaching should all be about.

\section{2. "Bilingual" teaching and learning}

\subsubsection{Different approaches to "bilingual" teaching and learning}

It is a well-known fact that there are different approaches to the topic of "bilingual" teaching and learning. The most noticeable difference between the existing approaches is to be found in the sociocultural surroundings of the teaching/learning institution in 
question. From the perspective of societal bilingualism, we find that in the Canadian province of Québec, there is the immediate or perceived need to teach both official languages to every citizen. In Luxembourg or Belgium, where there are even three official languages, the citizens might be supposed to have at least a working knowledge in all of them. However, considering those two countries, individual bilingualism is widespread only in Luxembourg. Interestingly enough, in many officially bilingual or monolingual countries we find less individual bilingualism than in officially monolingual ones (Hoffmann 1991:13-14), because such countries pursue policies of territorial monolingualism, as happens for example in Belgium.

In general, there seem to be three basic types of bilingualism:

1. the prototypical type of bilingualism would be parallel bilingualism where the languages are used side by side, such as in Luxembourg - where we are actually not dealing with bilingualism but with trilingualism;

2. the second type: territorial bilingualism such as we find in Canada or to a certain extent in Belgium;

3. and the third type: functional bilingualism such as is currently developing in German foreign language education.

The prototypical type of parallel bilingualism is what one finds less often than the other two types. Luxembourg comes close, although it is perhaps not the best example as the languages are used in complementary distribution and thus might be considered to be used functionally. Still, it offers interesting insights insofar as language planning results are concerned. The indigenous population is nearly $100 \%$ trilingual (Lebrun \& Baetens Beardsmore 1993: 101). Territorial bilingualism departs from the prototype inasmuch as it does not refer to a whole nation but generally to border areas and smaller parts of a country. Still, in those areas we do find quite a parallel distribution of the two languages in question. These countries are officially bilingual, but function more like two (or more) monolingual areas within one nation. The third type, functional bilingualism, refers to nations which are officially monolingual but want their inhabitants to have at least a working knowledge of another language for specific reasons. Therefore, we still find a complementary distribution of language usage, but this would not be restricted to certain territories.

We will first take a look at Luxembourg: it is one of Europe's smallest nations with only about 350,000 inhabitants. It is officially trilingual, the three languages being German, French and Luxembourgish or Lëtzebuergesch. Each of these three languages is used for specific purposes in well-defined situations. Luxembourgish, which has had an official spelling since 1912 only, is used for all spoken communication apart from official speeches in which French would be used. It is also used in nursery schools and 
in the first years of primary school. German is the written standard language (journals, newspapers) and is also used for instructional purposes in primary schools, where during six years it progressively replaces the use of Luxembourgish, as well as in the first three years of secondary education. French is the first official language, used in politics and finance, and is also used as a medium of instruction, but only at secondary level from the fourth grade onwards. Furthermore, it is used for all official written communication. Generally, adults use all three languages in complementary distribution, and this is in accordance with the country's constitutional provision.

This means that small children grow up with Luxembourgish, but they would also have a growing awareness of and contact with the two other languages being used all around them. When they enter school, their knowledge of German -and later on of French - will be enlarged and standardised. Therefore, schooling in Luxembourg may be considered part of an immersion program because it is completely done in different languages from the one the children speak at home. Nevertheless, it differs from the Canadian Early Total Immersion Programmes as the foundations of education are laid in the L1.

Let us now consider Canada: Canada is officially a bilingual state and the rights of the French-speaking minority are guaranteed in the constitution (Languages Act of 1969). This, however, could only come about after a prolonged political struggle during which the French-speaking province of Québec had threatened to leave Canada. Furthermore, little has been done so far for the other Canadian linguistic minorities, such as the indigenous Inuit language.

Canada's educational system is deliberately geared towards fostering bilingualism, therefore children from the English-speaking majority are enrolled on a voluntary basis into French immersion courses in Canadian schools. These measures are also seen as important for raising the minority language's prestige. There are plenty of studies (as cited for example in Baker 1988) about the results of such immersion courses, many of which rate the programs as very successful.

One of the major outcomes that has been observed after Canadian English-speaking children have gone through immersion programs is the marked decline of prejudices against the Franco-Canadian minority (in Canada, French is less prestigious than English): the children felt at ease in French social settings, expressed positive feelings towards French-speaking people and started to identify with Canadian as well as European French culture (cf. Lambert \& Tucker 1972). As researchers feel confident that no loss of the English identity has occurred, we are dealing here with a case of additive bilingualism.

Another political means used in Canada for enhancing the use of the minority language consists in the use of the minority language in the realms of administration, industry and business (Bill 101 of 1977). Furthermore, state employees who are fluent 
in both official languages get better pay. However, these programs also meet with problems, especially outside the French-speaking province of Québec, in which French is the only official language. In Québec, French-language education has been readily available for a long time but, outside the province, the bilingual programs have only recently been set up. Thus, it is not only a question of supporting bilingual education, but also of reallocating the French language in the domain of business and commerce, where it did not play an extensive role before.

In Belgium, we find a different kind of situation. Belgium incorporates "three linguistic minorities" (term borrowed from Hoffmann 1991: 223). The two major language groups, i.e. French and Dutch, have constituted themselves into federations of their own free will, and the language groups that came together have achieved equal official status for their languages (what Pohl 1965 calls horizontal bilingualism), albeit only after a fair amount of struggle. Unofficially though, Dutch used to enjoy a lower social prestige in Belgium than French did, and the same is true for French in Canada. What has happened in Belgium then, is that the speakers of either language may remain monolingual, as most French-speaking Belgians indeed do and what the Flemish could not do historically, since Dutch-language secondary education in Dutch-speaking parts did not become legal until 1930. So for 100 years, Belgium was an officially Frenchspeaking country. Still today, most of the Dutch-speaking Belgians prefer not to remain monolingual. The third language in Belgium, German, is a regional official language and is spoken in a very tiny territorial stretch on the border to Germany, centring around the cities of Eupen and Malmédy.

The distribution of the languages across the nation, however, is always in a certain flux. Brussels, for example, is situated at the extremity of Flanders and used to be predominantly Dutch-speaking till 1830. Nowadays, due to the centralisation of the country's administration which had worked exclusively in French for almost 100 years, due to E.U. internationalisation and also to urban migration, it has become a mainly French-speaking city. In general, although Belgian schools offer courses in the "other" languages, no learner is forced to take these courses, except for the Brussels area where the learners have to learn the other language as well. Therefore Belgian citizens -although living in a territorial multilingual country- are not Dutch-French bilingual or even multilingual individuals, although most educated people know English besides their mother tongue.

These different preconditions call for different types of learning organisation. Canada, and especially Québec, has started the so-called immersion programmes, where learners are surrounded all day long by the "other" language. Luxembourg switches languages: while German is the official language of primary and early secondary schooling, for the last 3 years learners have to switch to French. And Belgium leaves it 
up to the learners themselves (or to their parents) whether they want to learn the other language/s or not. Most French-speaking learners and parents choose English (about $60 \%$ ), whereas about $95 \%$ of Dutch-speaking learners and parents choose French and English $^{6}$.

\subsubsection{The German context}

As mentioned above, we are dealing with a totally different kind of situation in Germany. Although there are some millions of people in Germany who belong to linguistic minorities, Germany may basically be considered to be a monolingual country. However, German politicians and educators feel the need to enable German learners to use English (or French) in whatever context they might be supposed to need it. With the opening of the European job market and the globalisation of science, knowledge and industry, people should be prepared to use English "professionally", which always means to get higher-paid jobs. To reach this aim, it is just not enough to teach English in the traditional way of exposing the learners to 3 or 4 English lessons a week. They need to have more contact and to use English freely as a language of communication. Such reflections have led to the start of the so-called "bilingual" teaching programmes in all German federal states?

The history of "bilingual" teaching and learning in the German context is not that old. It goes back to the 1970s where this kind of teaching was introduced on a trial basis in some German high schools. Nowadays, all German federal states have joined this trend in at least some of their schools. Most of the "bilingual" schools are to be found in the region of North Rhine-Westfalia. Generally, the second language used in these schools is English, sometimes French, especially in those areas bordering on France. But some junior schools ("Realschulen") have in the meantime also joined this movement as the insight grows that an intensive contact with the English language will be very useful in the learners' professional lives later on.

In the rest of Europe, the German trend is known as the "German Model" or as the "Modèle allemand" and is rather highly respected (Mäsch 1993). France has tried to copy some of the features of this German Model, which is also finding a positive echo in Asian countries (Mäsch 1995).

6. Personal communication by René Dirven.

7. See above for a discussion of the "bilinguality" of the concept of "bilingual" school education in Germany. 
The basis for the German Model is the "bilingual" teaching of some subjects, both the mother tongue and the foreign language being used as media of instruction. This is sometimes done by a team of two teachers, i.e. one native speaker and one German teacher of the other subject (Rhineland-Palatinate). In most other cases, however, the classes are taught by a single teacher who combines both subjects, i.e. the foreign language and the other subject. Both methods have their shortcomings: a dual job is very difficult to finance, given restricted budgets for schools; the second model does not guarantee that this teacher is able to teach the other subject in English in a didactically adequate way, or that s/he commands the foreign language sufficiently for various school subjects, which are quite different from every-day language use.

To find a remedy to these problems, some German universities (such as Bremen) have started extra programs within their foreign language teacher-training departments, where learners who are studying both subjects (i.e. the foreign language plus a suitable other subject) are offered special courses in "bilingual" teaching methodology, development of teaching materials, didactics and psychology of "bilingual" teaching and learning, and related matters. Given that all future teachers have to do two years post-university training, some of the institutes where this is done are taking the same positive path. There, the teacher trainees get extra training in special courses as well as in "bilingual" schools.

The programs of "bilingual" teaching and learning have been established under the influence of the political vision of a unified Europe where plurilingualism is a highly desired quality. In some European nations like Belgium or Luxembourg (see above), plurilingualism is a traditional asset, but not so in Germany. Therefore it seems to be very useful to endow German learners with a certain level of "bilinguality" in order to prepare them for their jobs (within a plurilingual Europe), to enable them to study in an English-speaking country, or to travel and to work within Europe without language being a barrier. Furthermore, learning a foreign language intensively means at the same time learning about the foreign culture. Thus, "bilingual" classes are confronted with insights into the other culture or other cultures and thus learn to understand it/them and get rid of possible prejudices. At the same time, learners are expected to acquire this skill as a general strategy which might be used as well for contacts with other cultures.

The "bilingual" teaching does not start immediately when the children enter secondary school at the age of 10 . For the first two years, they participate in an intensive course in the target language, usually getting two English lessons per week more than in a normal class, which prepares them for the "bilingual" classes to follow. In the third year, the first "bilingual" subject will be introduced, for example history. In the following years, in most cases two more subjects will be taught "bilingually" as well, but usually the syllabus never contains more "bilingual" subjects than two at a time. The 
learners in these "bilingual" classes learn about similar topics as their "non-bilingual" colleagues do, but with the added value of a heightened exposure to the foreign language. The "other subjects" and the foreign language teaching as such, i.e. English or French taught as school subjects, are supposed to be closely co-ordinated and to mutually support each other.

At the end of each year, the learners are evaluated and get their grades according to their achievements in the subject(s) in question. Their linguistic achievements are acknowledged as well, but stay more in the background and are only allowed to influence the grade in a positive way, but not in a negative one. At the end of their school careers, learners get a final school report which mentions their achievements in the "bilingual" classes. In the French border regions, they even have the possibility of acquiring the German "Abitur" and the French "bac" at the same time.

In the last ten or so years, more and more German secondary schools have been showing their interest in offering "bilingual" classes, and the parents and learners accept this model very willingly. What is more, the principle of using the foreign language in (quasi-)authentic situations and to get across "real" opinions and cognitive content has already managed to influence the more traditional kind of foreign language teaching as well, so that language teaching/learning may continue to become ever more learnercentred and more motivating.

\section{IS LIVING WITH TWO LANGUAGES LIVING IN TWO WORLDS?}

Being bilingual does not only mean living with two languages, but may at the same time mean being bicultural. Admittedly, bilingualism and biculturalism do not necessarily go hand in hand; people can be monolingual and bicultural, such as for example English-speaking Scots or French-speaking Bretons, as well as bilingual and monocultural, such as happens for example in Luxembourg or in countries with a lingua franca, e.g. in Tanzania or in Kenya (cf. Grosjean 1982: 157-158). But I would like to focus on the prototypical bilingual child growing up with parents from two different cultures. Even if that child can not live in two cultures at the same time, it will certainly notice influences from both of the two cultures, especially when the parents do not willingly try to suppress one of those cultures. This may refer to a certain manner of celebrating holidays or other festivities, or to a certain kind of interactional behaviour, or also to subconscious attitudes and nonverbal behaviour in general. Language in its broadest sense is culture, and transmits cultural values and norms. 
How does this affect the bilingual child? Is it torn between two cultures? In the best of all cases, the second culture is added to the first one. This can be shown by a very trivial example referring to cultural values and traditions, e.g. in a German-Spanish family Christmas would not only be celebrated the German way on December 24, but also the Spanish way on January 6. The children will soon learn that in their family there are some "extras" which other, monocultural families do not share. Much depends on the parents' attitudes towards those extras. The culture in which the bicultural family lives will often be the dominant one, but the other culture will also exert its more or less conscious influence. The children may question this, and by doing so, they may learn even more about the second culture.

Grosjean (1982: 159) gives the more intricate example of an English-French bilingual that had problems with the distinction between $t u$ and vous for which there is no equivalent in the English language. This distinction is hard to grasp for monolingual French - as well as German - children anyway, but it may be even more difficult to also switch concepts of politeness when switching languages.

In certain situations, some children may also feel torn between their two cultures. Thus, in a monocultural group of their first culture, they may feel themselves the "odd ones out" and, when staying in their second culture, they may also be regarded as foreign and strange. However, their bonds towards those cultures will be much stronger than those of real outsiders, so that they should soon feel the importance of their double cultural identity. According to Grosjean (1982: 160), complete biculturalism does not exist: it "does not usually involve keeping two cultures and two individual behaviors separate"; but it is more normal to find persons "who combine(s) traits of the two different cultures" (1982: 161). In order to achieve this, children may need help in some cases. However, it is here that official educational policies - at least in Germany - often fail.

How far, then, would living with two languages equal living in two worlds? One might claim that always that language and that culture of the nation where the child is currently living are the more dominant ones, at least if that period of residence lasts long enough and if there are enough contacts to people from the surrounding culture. Thus, when a Spanish/German-bilingual child lives in Germany, the German culture will predominantly be the culture the child refers to and is better acquainted with. However, the strength and presence of the Spanish culture depends very much on that parent who is Spanish and on her or his ability to make that culture a part of everyday life. Today, this is still easier for the mother than for the father, because due to our socio-economic role distribution the mothers spend more time with the children and are usually the ones that make the children aware of cultural details and explain them.

For example, when the mother has to explain the concept of "greeting people, according to the degree of acquaintance one has with them" she can only explain that 
concept that she herself has internalised. If her concept is different from the one of the surrounding culture, the children will first notice that their behaviour is somehow deviant, and then they may quickly adapt to their surroundings. Should they stay for a while in their mother's culture, they will soon discover that there, the "old" concept is a valid one and they will adapt their behaviour in turn. All this will happen largely subconsciously but the underlying concepts and norms that have been established and entrenched over time will have to switch from one culture to the other. One could imagine a similar scenario concerning the notion of politeness. When an English/German-bilingual child learns to add "please" to all kinds of utterances and does so when speaking German as well, in contact with German children s/he will soon learn not to do so any more. Thus, culture-bound behaviour and behaviour concepts are largely context-dependent.

Switching between these kinds of contexts is not too easy for smaller children, but the older they get and the more experience they have gathered with both cultures in question, the more smoothly these switches may occur. It is a completely different question whether children from bicultural families want to adapt to those two cultures. Especially at the age of puberty children often reject their parents' values altogether and try to conform to the norms and attitudes of their peer groups, thus at the same time rejecting the "other" culture although they will be unable to completely evade its influence.

\section{THE CONCEPTUAL INTERFACE}

Keeping the above reflections in mind, how can they be transferred to "bilingual" learning and teaching? The situation is certainly less evident when we are not dealing with natural bilingualism but with that kind of bilingualism induced by learning institutions. German children in a "bilingual" school will certainly have internalised German labels for German concepts. If they learn to stick English labels onto the German concepts, this may seem good enough for a start, and naturally enough for the first words to be learnt; however, this leads them along the wrong track. Even concrete concepts are not completely comparable in those two cultures: thus, for example, "Bus" does not refer to the same concept as bus does. There are even more striking intercultural differences for more abstract concepts. Therefore, teachers should from the beginning aim at establishing a new network of meaning where English labels are used for English concepts (British, American or whatever) and where translation interferes as little as possible.

How could this be done? We will try to demonstrate this by an example from vocabulary teaching. New words should never be introduced in isolation, but always inside a word-field, or a category. Furthermore, the teacher should show the learners 
several approaches to the new word/s. Thus, to stick to the example bus, the teacher could visually introduce the category vehicle with its different members, including coaches and the typical London bus, and label those vehicles. Furthermore, the German category "Fahrzeuge" could be worked out by the learners for contrastive reasons. The lexeme bus should also appear in different contexts in order to show the learners how this word may be used.

For more advanced learners, the teacher could introduce the concept of metonymy by referring to colour expressions (see also Niemeier 1998). Thus, expressions such as blue-eyed boy or to see red can be traced back to underlying metonymic meanings, which again are culture-dependent and thus often not readily translatable. Such an exercise can be enlarged rather easily, in so far as learners may look for other metonymic or metaphoric expressions incorporating colour terms in the two languages in question, and in a second step, compare the different meanings that the colour terms can have in those two languages. They will find out that the colour term itself does not incorporate connotations, but that there are different underlying meaning extensions and concepts in both of the languages analysed.

The above examples refer to English lessons as such. How can this approach be transferred to history lessons in English, or geography lessons in French, for example? It is here that the "bilingual" teacher needs to have a broad knowledge of "bilingual" teaching methodology and didactics. It is advisable, for instance, that topics referring to the particular English-speaking culture in question (such as the history of the British Empire or industrialisation in Great Britain) are dealt with in English only, whereas topics referring to the German culture and thus to totally different conceptual categories (like the Nazi regime or German reunification) are discussed in German. In this way, the teacher may be able to avoid as much as possible the mixing or blending of concepts or the forming of inadequate concepts on the part of the learners.

When we talk about letting the learners discover their own learning strategies, this does not mean that the teacher can rely on them to find the best ways and strategies on their own. In contrast, s/he must present a broad variety of possible strategies and possibilities in order to cater for all the different types of learners. $\mathrm{S} /$ he has to create an atmosphere of trust inside the classroom where nobody should be afraid of making a mistake. In "bilingual" lessons, this should be a given for both the language aspect and also the content aspect. The teacher should encourage the use of English (or French) and act as a perfect role model for the learners, but s/he should also get them to work on their knowledge about the subject in question. This might of course imply that some of the weaker learners resort to their mother tongue - which is not a tragedy in itself but which should be avoided as much as possible during an "English" phase. The learners will soon develop better language skills because they will not feel monitored and do not always 
feel that they have to perform at their best; therefore they will develop more fluency and more confidence in using the foreign language in a quasi-authentic situation.

What will become a problem, however, is the fact that the learners will want to try to express the concepts that they learned in the foreign language in their mother tongue as well. At such crucial points, they will realise differences between the languages and the underlying cultural practices such as style of speech or conciseness. This experience is rather helpful and should therefore not be avoided. And it is also at this juncture that they start to realise that they have the ability to live "in two worlds" - if they want to. In contrast to naturally bilingual children, these learners can consciously choose between the two languages and may even choose an interim space, i.e. living in their own idiosyncratic language world (the well-known and well-researched "inter-language", cf. Selinker 1992 or Corder 1981), which may incorporate elements from both languages.

What happens in their minds when the learners find themselves at such a juncture? They have internalised the conceptual world of their first culture and of their first language and are now confronted with a challenge to this internal architecture as they realise that it does not fit their new, second language any more. They have to shed their cultural egocentrism and be willing to acknowledge the existence of different concepts. And it is exactly at this point that the teacher has to intervene. As mentioned above, the mother tongue labels should not be exchanged for the foreign language labels. What the teacher should try to aim at instead is to enable the learners to construct a second conceptual mini-world (i.e., realistically speaking, small parts or building-blocks of it) and although those two conceptual worlds should be kept apart, there should also be opportunities for them to interact. In this way, the learners will also have a brilliant access to seeing and interpreting intercultural differences. If vocabulary items are introduced in thematic fields, this aim is more easily achieved than if they are introduced as unrelated single entities because, inside the thematic fields, the culture-related categories rest intact and each single item has its own place within the category and its inherent boundaries towards the other category members.

With respect to the introduction of a new conceptual world, it also becomes clear that there is no place for translation within the English or the "bilingual" classroom because, in translation, category members are being transferred to another category of a different conceptual world and thus, will be out of place. In more harmless cases, such as house being translated by "Haus", one might argue that those two items may be considered to be members of a more universal category "building". One might

8. There is also quite a difference between the frequency of usage of those two terms. In German, "Haus" is used much more infrequently than in English, due to the fact that most people live in a "Wohnung" and not in a "Haus", whereas in English, there is not even a word for "Wohnung" (flat or apartment). 
counterbalance the treacherous identity effect by showing pictures of a typical German house and a typical British or, say, American one, but nevertheless, the learners might still think about one item with two labels, especially with regard to the phonetic similarity. In stronger cases, such as heaven and sky being both translated as "Himmel", one should make it clear to the learners that in English, there is the same denotatum, but two different designata in complementary distribution. And this explanation does not even try to account for the different meaning extensions and associations which are connected to these terms!

The fact that English and German are such closely related languages also points to the danger of confounding the underlying culture-related concepts or probably mixing them up. As in general we do not have two teachers per class (one for the English phases, one for the German phases) - as would happen in a bilingual family - the teacher as well as the learners have to switch between the two conceptual worlds according to the topics discussed. However, considering the fact that "bilingual" teaching starts in $7^{\text {th }}$ grade (age group 13/14), one may assume that the learners should have reached an age where such a switch should not present a major problem. Nevertheless, they would never be able to switch as easily as a naturally bilingual person can do, because they are still learning, whereas the naturally bilingual person already knows the two languages in question.

However, there will certainly always be very frequent interferences from the first conceptual world to the second conceptual world, just because this first conceptual world is so deeply entrenched, and as mentioned above, this is the point where the teacher should offer inductive as well as deductive ways of showing the learners where they went wrong, e.g. by giving explanations or inducing comparisons. These kinds of remedies work best, of course, if the teacher is her- or himself a bilingual and bicultural person - otherwise the explanations may be too much contextualised inside the German culture. This is of course asking a lot of the teacher person - and in this context, it is a very positive kind of development that at least in some German universities (such as Bremen) would-be-teachers have to spend time, i.e. have to study or teach, in a culture where the target language is spoken.

\section{CONCLUSION}

It may have become obvious that Germany is only just beginning to be interested in "bilingual" teaching and learning models and methods. There is still much to do, but the beginnings seem rather positive. Teachers, learners and also parents are much in favour of the new learning and teaching arrangements and want to participate in them. 
Still, much remains to be done. First of all, teacher training for the "bilingual" schools is barely in its infancy and, as long as there are no major innovations within German universities, schools will have to try to help themselves by looking for suitable persons among their own group of teachers. Those teachers, not really qualified for what they are supposed to do, also get the extra workload of developing new teaching materials for the "bilingual" classes because there is not much good "bilingual" teaching material commercially available. This is mainly due to the fact that there are so many different types of "bilingual" schools about, because there are no clear regulations nor legal requirements.

So why should teachers, teacher trainers and school administrators go to such lengths to establish this new kind of school education in Germany? Several reasons come readily to mind:

(1) In the wake of a kind of cognitive renewal of science and a general trend towards a holistic approach to science, learners should be confronted with a more holistic view of learning. Thus, learning should not take place in small bits and pieces, but aim at integrating all mental capacities of the learners at once. Therefore, artificial boundaries between subjects should be abandoned, creating a space for integrated, meaningful learning and aiming at activating the learners' full potential. Thus, if subjects such as biology and history are taught in English, and if the English lesson treats topics such as our responsibility for an ecologically healthy environment, then learning itself becomes much more meaningful and motivating.

(2) Learners profit from an enhanced exposure to the foreign language, especially when considering the European global market. If we want our learners to participate actively here in a European dimension, we must enable them to communicate in any kind of European surrounding. As the -unofficial- working language of the European Union is English, we must offer our learners as much exposure to English as possible. The best solution is certainly a prolonged stay abroad, but apart from that, teaching in English -as many subjects as possibleseems to offer a second-best solution insofar as it entails much more exposure to the foreign language, such as discussions which quite naturally take place in English and offer more authentic ways of speaking than the traditional English lessons with their focus on grammar skills do.

(3) Learners also profit from a deeper insight into a foreign culture. By slowly acquiring a second conceptual mini-world view, they are at the same time enabled to regard their own culture from a different, more neutral vantage point. Often enough, they discover very interesting aspects about themselves and their own culture; this leads them away from stereotypes and prejudices concerning 
other cultures and worldviews. Language and culture are inextricably intertwined, so learning a foreign language entails learning about a foreign culture as well, an issue that should not be neglected, especially when it comes to professional requirements for future "Euromanagers".

(4) Studies on natural bilingualism, such as Lambert \& Tucker (1972), have shown that living with two languages is a very positive asset, contrary to whatever other objections were raised before. Bilingual children are not confused by their two languages but are able to switch between them and to reflect on strategies of language usage. This may be the same for institutionally induced bilingualism such as we have been talking about in the German educational context. We are offering those learners a chance to enlarge their worldview in general and their linguistic abilities and strategies in particular. This said, one can only hope that more "bilingual" learning and teaching will be introduced into German schools and that those "bilingual" classes that already exist will lose their reputation as being part of an "elite education".

\section{ACKNOWLEDGEMENT}

I would like to thank René Dirven (University of Duisburg, Germany) for his comments on a first draft of this paper and Logie Barrow (University of Bremen, Germany) for checking my English. All remaining flaws are of course entirely my own responsibility.

\section{REFERENCES}

Artigal, J.M. 1991. The Catalan Immersion Program: A European Point of View. Norwood, N.J.: Ablex.

Baetens Beardsmore, H. (ed.). 1993. European Models of Bilingual Education. Clevedon: Multilingual Matters.

Baker, C. 1988. Key Issues in Bilingualism and Bilingual Education. Clevedon: Multilingual Matters.

Butzkamm, W. 1992. "Zur Methodik des Unterrichts an bilingualen Zweigen". Zeitschrift für Fremdsprachenforschung 3, 1: 8-30.

Canadian Education Association 1992. French Immersion Today. Toronto: Canadian Education Association.

Cole, R. 1975. "Divergent and convergent attitudes towards the Alsatian dialect". Anthropological Linguistics 17: 6. 
Corder, S. P. 1981. Error Analysis and Interlanguage. Oxford: OUP.

Cummins, J. 1978a. "Bilingualism and the development of metalinguistic awareness". Journal of Cross-Cultural Psychology 9: 131-149.

Cummins, J. 1978b. "Educational implications of mother-tongue maintenance in minority-language groups". Canadian Modern Language Review 34 (3): 345-416.

Cummins, J. 1984. "Linguistic minorities and multicultural policy in Canada". Bilingual and Multicultural Education: Canadian Perspectives. Ed. J. Edwards. Clevedon: Multilingual Matters. 55-67.

Davis, K.A. 1994. Language Planning in Multilingual Contexts. Policies, Communities, and Schools in Luxembourg. Amsterdam: John Benjamins.

Fantini, A. 1985. The Language Acquisition of a Bilingual Child. Clevedon: Multilingual Matters.

García, O. (ed.). 1991. Bilingual Education: Focusschrift in Honor of Joshua A. Fishman. Amsterdam: John Benjamins.

Grosjean, F. 1982. Life with Two Languages. Cambridge, Mass.: Harvard University Press.

Hoffmann, C. 1991. An Introduction to Bilingualism. London: Longman.

Holmes, J. 1992. An Introduction to Sociolinguistics. London: Longman.

de Houwer, A. 1990. The Acquisition of Two Languages from Birth: A Case Study. Cambridge: Cambridge University Press.

Lambert, W. E. \& R. Tucker. 1972. Bilingual Education of Children: The St Lambert Experiment. Newbury House: Rowley, Mass.

Lambert, W. E. 1974. "Culture and language as factors in learning and education". Cultural Factors in Learning. Eds. F. Aboud \& R. D. Meade. Bellingham: Washington State College.

Lebrun, N. \& H. Baetens Beardsmore. 1993. "Trilingual education in the Grand Duchy of Luxembourg”. European Models of Bilingual Education. Ed. H. Baetens Beardsmore. Clevedon: Multilingual Matters. 101-120.

Lier, L. van. 1996. Interaction in the Language Curriculum. Awareness, Autonomy and Authenticity. London: Longman.

Mäsch, N. 1993. "The German model of bilingual education: An administrator's perspective". European Models of Bilingual Education. Ed. H. Baetens Beardsmore. Clevedon: Multilingual Matters. 155-172.

Mäsch, N. 1995. "Bilingualer Bildungsgang". Handbuch Fremdsprachenunterricht. Eds. K. Bausch et al. Tübingen: Francke. 338-342

McClure, E. 1977. "Aspects of code-switching in the discourse of bilingual MexicanAmerican children". Technical Report No. 44. Center for the Study of Reading, University of Illinois, Urbana-Champaign. 
Niemeier, S. 1998. "Colourless green ideas metonymise furiously". Kognitive Lexikologie und Syntax. Rostocker Beiträge zur Sprachwissenschaft 5. Ed. F. Ungerer. 119-146.

Pohl, J. 1965. "Bilinguismes”. Revue Romaine de Linguistique 10: 343-349.

Pütz, M. 1994. Sprachökologie und Sprachwechsel. Frankfurt am Main: Lang.

Rampillon, U. \& H. Reisener. (eds.). 1994. Bilingualer Unterricht (= Der fremdsprachliche Unterricht: Englisch) 28, 15.

Reyes, R. 1982. "Language mixing in Chicano English". Spanish in the United States: Sociolinguistic Aspects. Eds. J. Amastae \& G. Elías Olivares. Cambridge: Cambridge University Press. 154-165.

Sankoff, D. 1998. "A formal production-based explanation of the facts of code-switching". Bilingualism, Language and Cognition 1: 39-50.

Saunders, G. 1982. Bilingual Children - Guidance for the Family. Clevedon: Multilingual Matters.

Schmid-Schönbein, G. \& B. Siegismund. 1998. "Bilingualer Sachfachunterricht". Englisch Lernen und Lehren. Ed. J.-P. Timm. Berlin: Cornelsen. 201-210.

Selinker, L. 1992. Rediscovering Interlanguage. London: Longman.

Skutnabb-Kangas, T. 1984. "Children of guest-workers and immigrants: Linguistic and educational issues". Linguistic Minorities, Policies and Pluralism. Ed. J. Edwards. London: Academic Press. 17-47.

Timm, J.-P. (ed.). 1998. Englisch Lernen und Lehren. Berlin: Cornelsen.

Vihman, M.M. 1985. "Language differentiation by the bilingual child". Journal of Child Language 12 (2): 297-324.

Vygotsky, L. 1962. Thought and Language. Cambridge, Mass.: MIT Press. 